\title{
Determinants of polydipsia: IV. Free-reinforcement schedules'
}

EVALYN F. SEGAL, DAVID L. ODEN AND SAM A. DEADWYLER

SAN DIEGO STATE COLLEGE

\begin{abstract}
Abstraet
Rats got pellets on free-reinforcement (F) schedules with inter-pellet intervals from 30 to $480 \mathrm{sec}$. As the interval lengthened, drink frequency increased to a maximum and then decreased, average latency between pellet arrival and drinking increased, average drink duration increased, and licking rate within drinks decreased.
\end{abstract}

\section{Problem}

Stein (1964) argued that the fact that rats on FI bar-pressing schedules drank water shortly after arrival of pellet reinforcers, rather than shortly before the next pellet was due, proves that the drinking was controlled solely by thirst. He contended that if the drinking had been adventitiously reinforced by food, it should have occurred late in the fixed-interval, as bar pressing does. However, his argument neglects that bar pressing was the operant on which food was contingent, and so must have competed strongly with any tendency to drink late in the interval. Moreover, Segal's (1965) observation of what appeared to be a two-link adventitious chain of drinking and then bar pressing on a free-reinforcement schedule suggests that a response occurring early in the inter-pellet interval deserves as much to be called an adventitious operant as a response occurring late in the interval, provided that the two-response pattern is consistent over intervals.

Nevertheless, we accept Stein's (1964) reasoning that if drinking is adventitiously reinforced by food on an interval schedule, it ought to occur later in the interval as the interval is lengthened. Here we demonstrate that this is indeed the case.

\section{Method}

Two adult, male, albino rats were maintained at $80 \%$ of ad lib weight and given $45 \mathrm{mg}$ Noyes peanut pellets on $\mathbf{F}$ schedules in daily sessions in a soundinsulated chamber in a sound-resistent room containing white masking noise. The chamber had a bar, food cup and water nozzle, all electrically connected to counters and recorders. The order of the inter-pellet intervals, the number of sessions at each interval, and the lengths of sessions are indicated in Fig. 1. Starting with the second series of $\mathrm{F} 60$, and on occasion thereafter, other treatments were administered following the sequence of sessions indicated in Fig. 1 , and before moving to the next $\mathrm{F}$ value. They included injection of amphetamine or pentobarbital, extinction sessions with or without the operation of the empty pellet dispenser, free-feeding of $45 \mathrm{mg}$ or $4 \mathrm{gm}$ food pellets

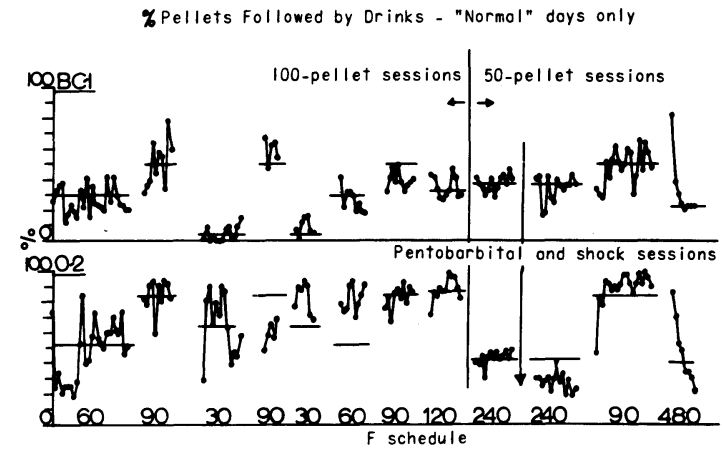

Fig. 1. Per cent of inter-pellet intervals that included drinking, for all days prior to drug or shock sessions.

in the chamber, and brief electric shock at the beginning of sessions. None of these data is reported here. All data reported here are based on the median of the last five days at a given $F$ value, before any unusual (e.g., drug) treatments started. The data of Fig. 2 are means of the medians from all series at the same $F$ value, for panel $A$; and means of the corresponding days for the other panels (i.e., days corresponding to median per cent pellets-followed-by-drinks).

\section{Results}

The data of Fig. 1 and 2 speak for themselves. As inter-pellet interval lengthened, per cent of intervals including a drink increased to a maximum at 120 or $240 \mathrm{sec}$. and then decreased; pause between arrival of a pellet and initiation of a drink (computed only for in te rvals that in cludeddrin $\mathrm{ks}$ ) increased monotonically; drink duration increased monotonically, and the rate of licking within drinks fell, roughly monotonically.

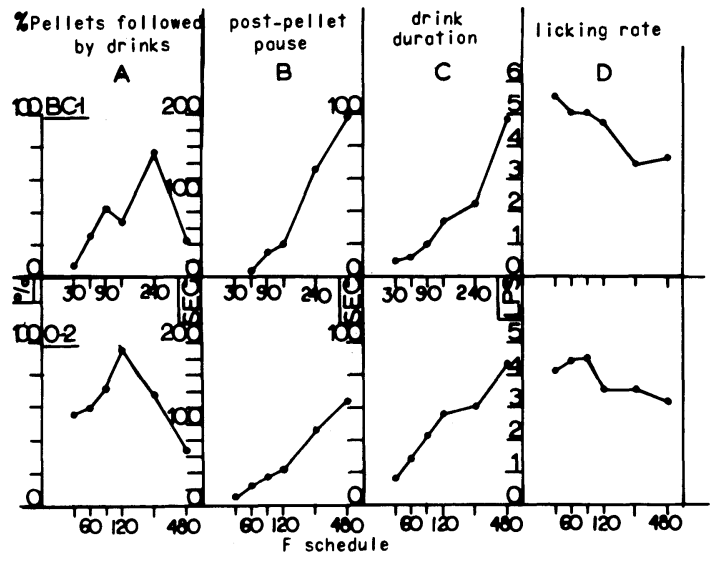

Fig. 2. Average data for the whole experiment. Explained in text. 


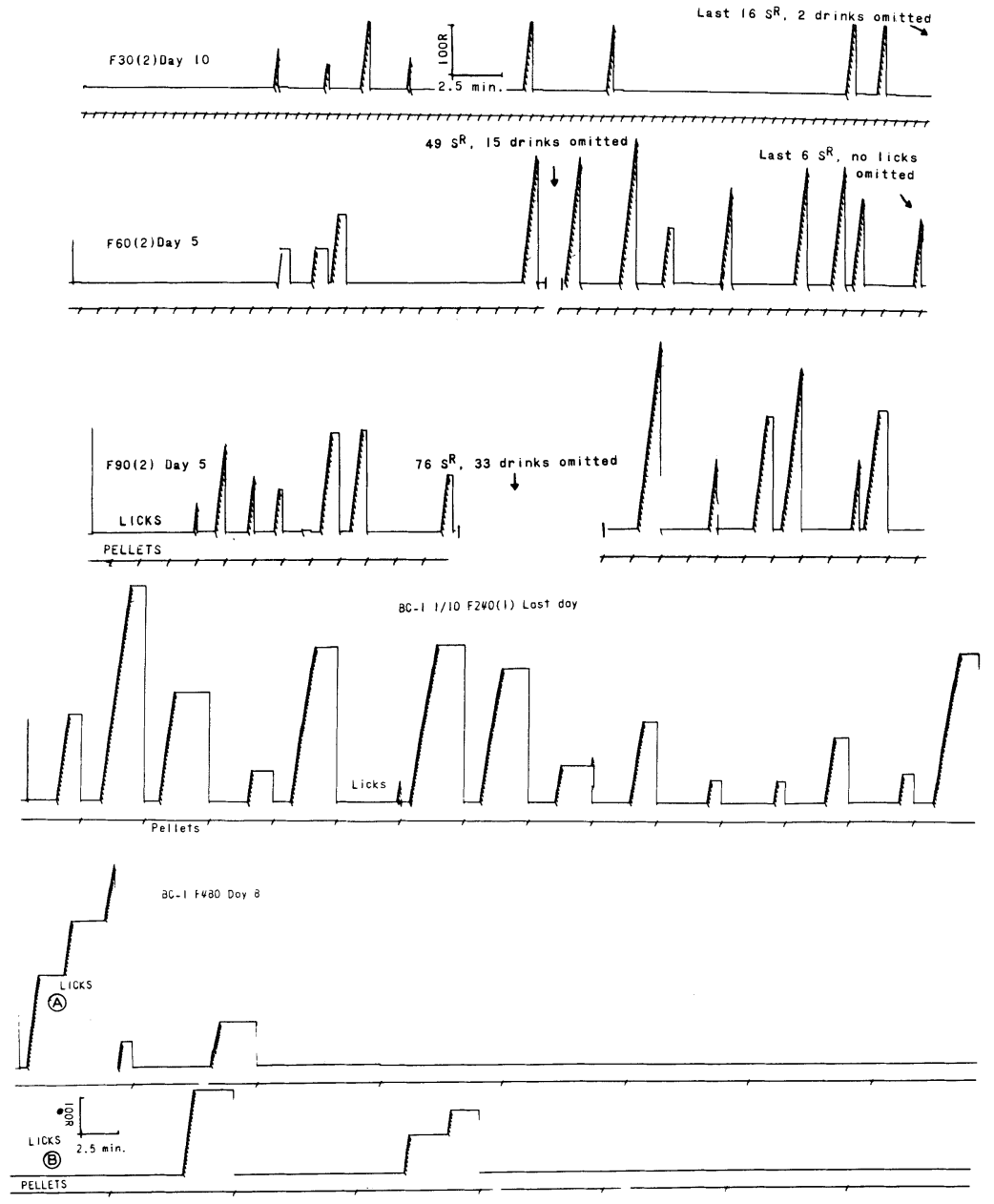

Fig. 3. BC-1's drinking on selected sessions at F30, 60, 90, 240 and 480 . Initial portions of sessions only.

The horizontal lines drawn through connected sets of points in Fig. 1 are visually estimated approximate medians of all points of the $\mathrm{f}$ i $\mathrm{rst}$ series at any given $\mathrm{F}$ value, and permit an estimate of the recoverability of data over the experiment. For example, both sets of points at $\mathrm{F} 60$ varied about the same median, for $\mathrm{BC}-1$, but the data for the second $\mathrm{F} 60$ series were considerably above the median for the first series, for 0-2. Generally, BC-1 showed somewhat better recoverability than 0-2. Particularly interesting, but unexplained, is the reliable decline in F240 data for 0-2 following a sequence of sessions involving pentobarbital injection or electric shock.

Figure 3 shows drinks by $\mathrm{BC}-1$ during portions of the last session (before drug,etc.) at a given $\mathrm{F}$ value (F120 is not shown). The data are from the second series at F30, F60 and F90, but the first series at F240 and F480. Pellets reset the licks pen, marks below show the delivery of pellets, and deflections in the licking records mark the passage of 2 sec. of drinking. Especially clear in the figure is the lengthening of the interval between pellet arrival and initiation of drinking, as the $F$ value lengthened.

\section{Diseussion}

Records of food-cup contacts indicate that the reason for the low frequency of drinking at lower $F$ values, especially F30, was competition from the behavior of remaining at the food cup throughout the inter-pellet interval. As the interval lengthened, this superstition gave way more and more often to drinking. At the longest F values, the drinking "superstition"' (if such it was) was much weakened. It appears that the Ss were not able to adjust their licking rate, drink duration and post-pellet pausing sufficiently to maintain FI-like drinking through such long intervals. If the Ss are capable of drinking only so much per drink and no more, for physiological reasons, then drinking might have become slightly aversive at the long intervals, and so ceased long before pellet arrivals, and so broke the adventitious contingency between drinks and food.

\section{References}

Segal, Evalyn F. The development of water drinking on a dry-food free-reinforcement schedule. Psychon. Sci., 1965, 2, 29-30. Stein, L. Excessive drinking in the rat: Superstition or thirst? J. comp. physiol. Psychol., 1964, 58, 237-242.

\section{Note}

1. Supported by NSF GB 1605, NIMH 8505, and an NSF Undergraduate Research Participation Grant. 